\title{
AMENDMENTS
}

\section{Author Correction: A regulatory T cell Notch4-GDF15 axis licenses tissue inflammation in asthma}

Hani Harb (D), Emmanuel Stephen-Victor, Elena Crestani, Mehdi Benamar, Amir Massoud, Ye Cui, Louis-Marie Charbonnier (D, Sena Arbag, Safa Baris (D), Amparito Cunnigham, Juan Manuel Leyva-Castillo, Raif S. Geha, Amirhosein J. Mousavi, Boris Guennewig, Klaus Schmitz-Abe, Constantinos Sioutas, Wanda Phipatanakul and Talal A. Chatila (D)

Correction to: Nature Immunology https://doi.org/10.1038/s41590-020-0777-3, published online 14 September 2020.

In the version of this article initially published, in Extended Data Fig. 5a, the microscopy images from the OVA-treated Foxp $3^{\text {YFPCre }}$ mouse and the OVA+UFP-treated Foxp $3^{\text {YFPCre }}$ Stat $3^{\Delta / \Delta}$ mouse were almost identical due to an inadvertent duplication. New images were taken for all of the samples in the panel to ensure all of the images are correct, and these are shown below. The data in the other figure panels are correct and are therefore unchanged. The error has been corrected in the HTML and PDF versions of the article.

a
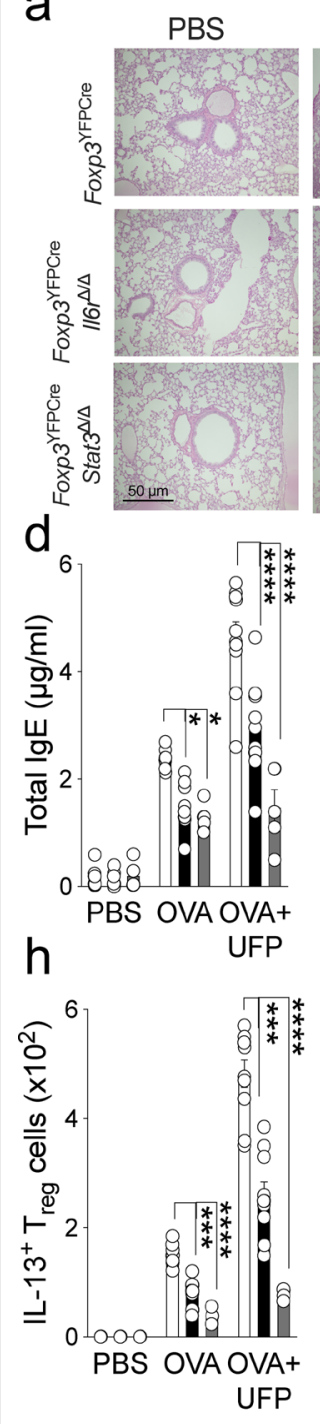

OVA

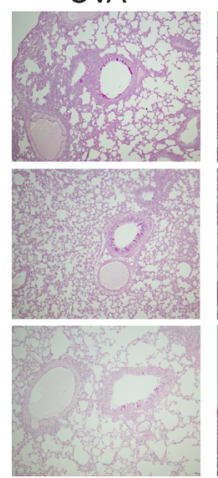

e

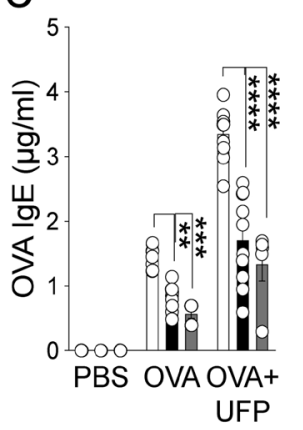

OVA+UFP
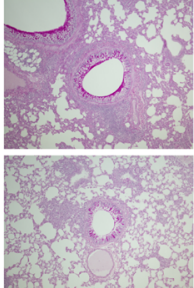

b
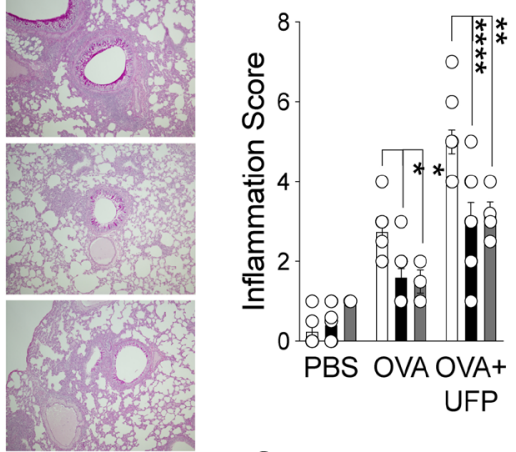

UFP
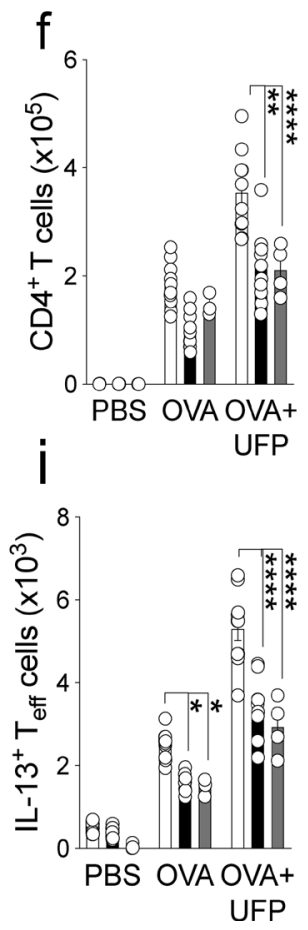

C

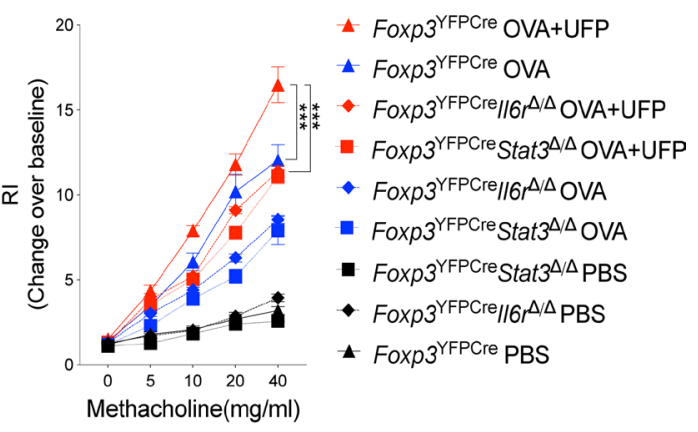

$g_{8}$

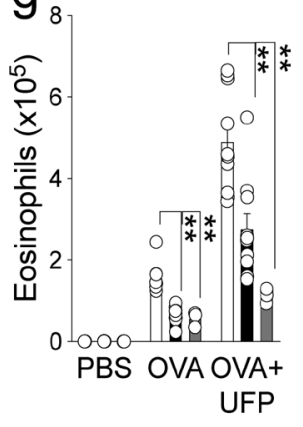

$\square$ Foxp3 $3^{\mathrm{YFPCre}}$

- Foxp3 $3^{\mathrm{YFPCre}} / 16 r^{\Delta / \Delta}$

$\square$ Foxp3 $^{\text {YFPCre }}$ Stat3 $^{\Delta \Delta}$
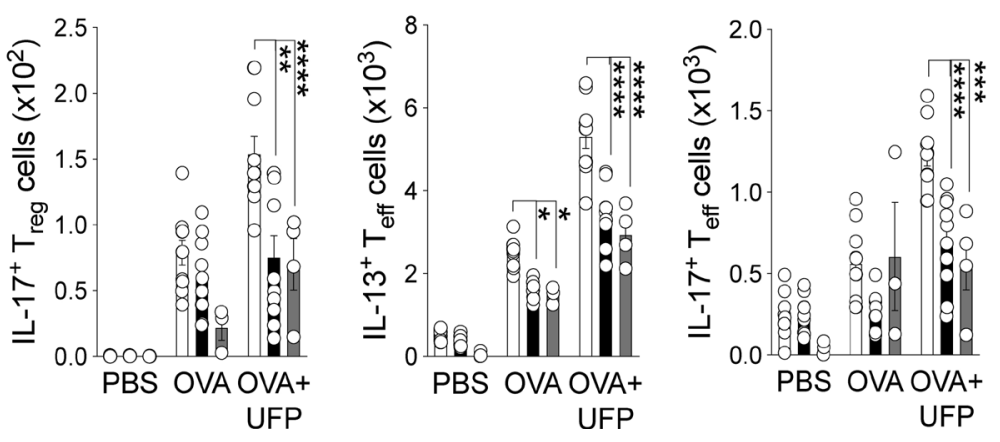


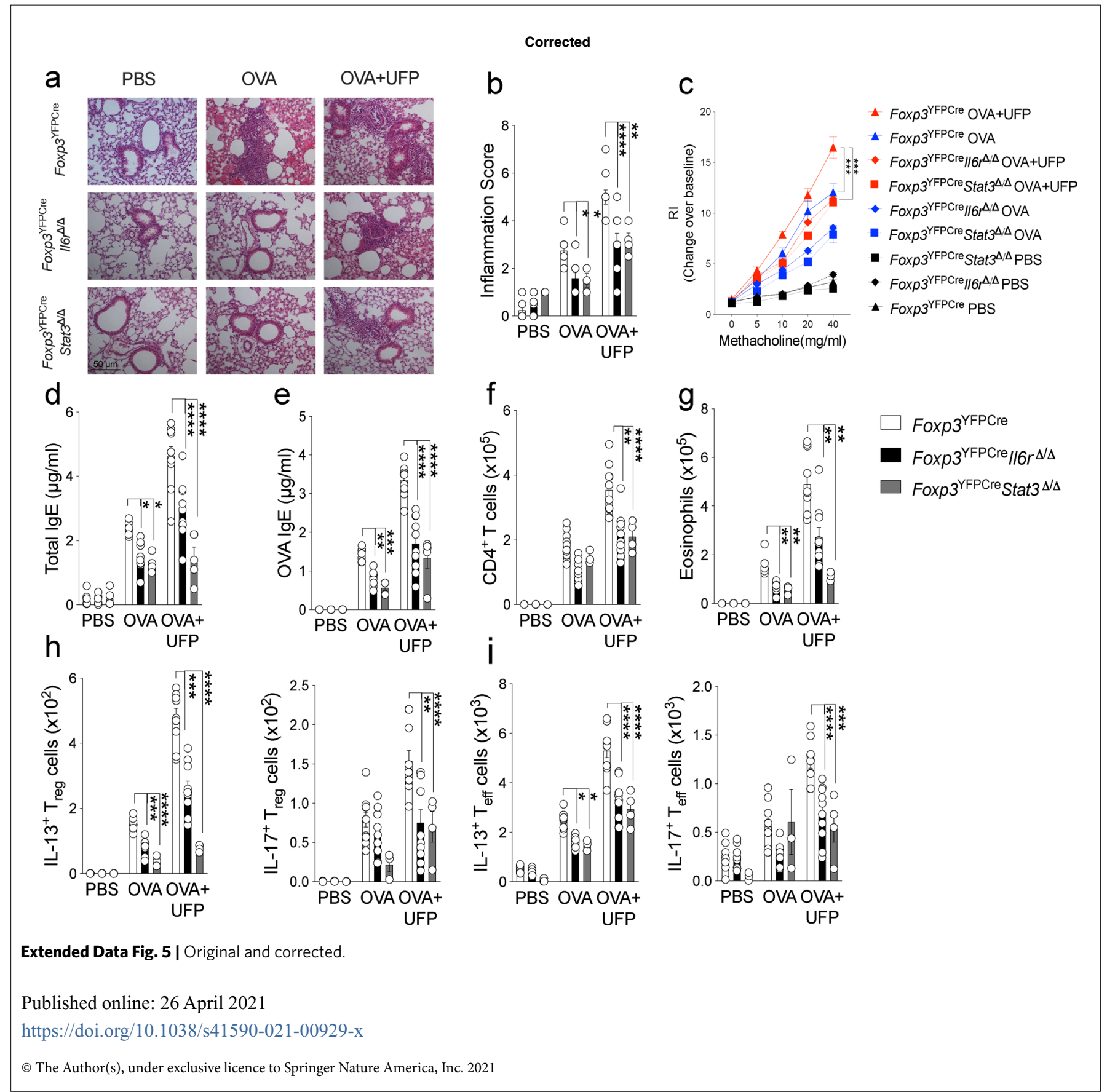

\section{Publisher Correction: Fiber-poor Western diets fuel inflammation}

Robert T. Patry and Cathryn R. Nagler (D)

Correction to: Nature Immunology https://doi.org/10.1038/s41590-021-00880-x, published online 11 February 2021.

In the corrected version of this article, in Fig. 1, the red and green arrows in the bottom panel were oriented incorrectly. The green arrow next to TNF, IFN- $\gamma$ and IL- 6 should be pointing up, and the red arrow next to IL-10 should be pointing down. The error has been corrected in the HTML and PDF versions of the article.

Published online: 26 April 2021

https://doi.org/10.1038/s41590-021-00932-2

(๑) Springer Nature America, Inc. 2021 